\title{
Chemotherapy or Combined Modality Therapy for Early-stage Hodgkin Lymphoma
}

\author{
JORDAN A. TOROK ${ }^{1}$, YUAN WU ${ }^{2}$, JUNZO CHINO ${ }^{1}$, LEONARD R. PROSNITZ ${ }^{1}$, \\ ANNE W. BEAVEN ${ }^{3}$, GRACE J. KIM ${ }^{1}$ and CHRIS R. KELSEY ${ }^{1}$ \\ ${ }^{1}$ Department of Radiation Oncology, ${ }^{2}$ Department of Biostatistics and Bioinformatics, \\ Duke University, Durham, NC, U.S.A.; \\ ${ }^{3}$ Department of Medicine, Division of Medical Oncology, \\ University of North Carolina, Chapel Hill, NC, U.S.A.
}

\begin{abstract}
Background/Aim: Optimizing treatment of earlystage Hodgkin lymphoma $(H L)$ requires balancing cure with potential acute and late toxicities from treatment. We reviewed our institutional experience with chemotherapy alone (ChT) versus combined modality therapy (CMT). Materials and Methods: Patients with stage I-II classical HL in a complete response $(C R)$ by functional imaging after chemotherapy were included. Progression-free survival (PFS) and overall survival (OS) were calculated and a multivariate analysis (MVA) was performed. Results: A total of 136 patients with a CR to chemotherapy were identified. Consolidation radiation therapy (RT) was administered to 117 while 19 received no further therapy. PFS (5 years) was $97 \%$ with CMT and $84 \%$ with chemotherapy alone ( $p=0.02)$. Long-term (10 year) survival was no different (96 vs. 94\%, $p=0.8$ ). On MVA, CMT improved PFS. Secondary malignancies were rare and no cardiac events were observed. Conclusion: Consolidation RT results in superior PFS in early-stage Hodgkin lymphoma with minimal added toxicity.
\end{abstract}

Hodgkin lymphoma (HL) most commonly develops in young adults and is effectively treated in the overwhelming majority of patients with current treatment programs. This has driven efforts to maintain high cure rates while minimizing long-term toxicity of therapy. The optimal strategy to accomplish these two, potentially conflicting, objectives is controversial.

The management of early-stage HL is currently based on categorization into favorable and unfavorable subgroups (1),

This article is freely accessible online.

Correspondence to: Chris Kelsey, Department of Radiation Oncology, DUMC 3085, Durham, NC 27710, U.S.A. Tel: +1 9196685213, Fax: +1 9196687345, e-mail: christopher.kelsey@duke.edu

Key Words: Radiation therapy, consolidation, positron emission tomography, complete response, metabolic imaging. with bulky disease being a special category among those with unfavorable disease. Chemotherapy followed by consolidation radiation therapy (RT), commonly referred to as combined modality therapy (CMT), is considered standard in the setting of bulky disease. For patients without bulky disease, whether favorable or unfavorable, there is significant dispute whether chemotherapy alone or CMT is optimal. While CMT has consistently demonstrated superior disease control in numerous randomized trials compared to chemotherapy alone, the effect on overall survival has been mixed (2-5). Most of these studies were performed without metabolic imaging such as positron emission tomography (PET). A large database analysis found CMT use has declined over the past decade with only $45 \%$ of patients receiving such in 2011 (6).

CMT has generally been the preferred approach at our Institution. For the last 20 years, metabolic imaging, initially gallium and more recently position emission tomographycomputed tomography (PET-CT), has been utilized to assess chemotherapy response. In complete responders, consolidation RT has been the common practice with radiation dose based on risk group classification and number of chemotherapy cycles received $(7,8)$. We herein report our institutional experience of early stage HL in complete metabolic response after chemotherapy treated with or without consolidation RT, with a specific focus on long-term disease control and toxicity.

\section{Materials and Methods}

This institutional review board-approved retrospective study identified all patients treated at Duke University Medical Center for stage I-II classical HL from 1992-2012. Those with nodular lymphocyte predominant disease were excluded. Histology was confirmed by hematopathologists at our institution based on the World Health Organization criteria (9). For all patients, histologic subtype, stage, number of nodal areas by German Hodgkin Study Group (GHSG) criteria, erythrocyte sedimentation rate (ESR), presence of $B$ 
symptoms, extranodal disease, and presence of large mediastinal adenopathy (bulky disease) were noted. Baseline imaging studies consisted of computed tomography (CT) supplemented with gallium imaging in the early time period and PET-CT in the later time period. Stage was based on the Ann Arbor classification (10). Patients were categorized into favorable and unfavorable risk groups according to the GHSG criteria, including large mediastinal adenopathy (LMA, $\geq$ one-third maximum transverse thoracic diameter on PA chest radiograph), extranodal involvement, more than two involved lymph node areas, or an unfavorable B symptom/erythrocyte sedimentation rate profile ( $\geq 50 \mathrm{~mm} / \mathrm{h}$ without $\mathrm{B}$ symptoms or $\geq 30 \mathrm{~mm} / \mathrm{h}$ with $\mathrm{B}$ symptoms) (1).

Chemotherapy regimen and number of cycles were at the discretion of the treating medical oncologist but typically consisted of adriamycin, bleomycin, vinblastine and dacarbazine (ABVD). All patients in the analysis underwent chemotherapy response assessment using interim and/or post-treatment functional imaging (gallium or PET-CT). Patients who did not undergo such assessment were excluded. All PET-CT studies were read by an attending nuclear medicine physician. Visual assessment pre-dated regular use of Deauville scoring criteria and were generally scored as negative if FDG-uptake was less than in the mediastinal blood pool. Only patients who achieved a complete response to chemotherapy by gallium or PET-CT were included in this analysis, as chemotherapy alone would not be sufficient in the setting of an incomplete response.

For those who received CMT, RT generally followed involvedfield guidelines (11), with the original sites of disease treated with a margin to account for imaging uncertainties and day-to-day setup errors. The total dose and fractionation schedule was at the discretion of the treating radiation oncologist.

Statistics. Two sample $t$-test, Pearson's Chi-squared test and Wilcoxon rank sum test were used to compare CMT and chemotherapy alone patient characteristics. Kaplan-Meier survival curves were generated to calculate progression-free survival (PFS) and overall survival (OS) from the date of initial diagnosis. PFS events included lymphoma progression or death, with patients censored at the last follow-up at our institution. Overall survival was calculated from the date of diagnosis to date of death. For patients who were lost to follow-up at our institution, an institutional registry was utilized to capture mortality events. Cumulative incidence of second malignancy and crude rates of hypothyroidism were calculated. Hypothyroidism was scored if thyroid hormone replacement therapy was initiated based on clinical and laboratory findings. Cox regression was used for group comparisons. Prognostic factors included in the multivariate Cox modelling were treatment modality, age, favorable vs. unfavorable classification and number of cycles of chemotherapy. Other long-term toxicities were also captured including cardiac events and secondary malignancies.

\section{Results}

A total of 337 patients were treated for Hodgkin lymphoma at our institution between 1992 and 2012. After excluding patients without adequate diagnostic information $(n=8)$, nodular lymphocyte-predominant histology $(\mathrm{n}=19)$, advanced stage disease $(\mathrm{n}=127)$, and treatment with RT alone $(\mathrm{n}=22)$, 161 patients with stage I/II disease remained who were treated with CMT or chemotherapy alone.
Following combination chemotherapy, an additional 25 patients were excluded because of an incomplete metabolic response or lack of metabolic imaging. This left 136 patients with a documented complete metabolic response, 48 confirmed by gallium and 88 by PET-CT. Chemotherapy consisted of ABVD (86\%) or ABVD-hybrids (6\%) in the majority of patients. The median number of cycles was 6 (range $=2-8$ cycles). Consolidation RT was administered to 117 while 19 received no further therapy. In the CMT group, the median radiation dose was 24 Gy (range $=18-36 \mathrm{~Gy}$ ) administered in 1.5-2 Gy daily fractions. Patient and treatment characteristics can be found in Table I. Notable differences included more frequent staging with PET-CT (versus gallium) and greater proportion of females in the chemotherapy alone cohort.

Clinical outcomes. Median follow-up for survival was 9 years (interquartile range $(I Q R)=5.3-15)$ and for toxicity and progression endpoints was 5 years $(\mathrm{IQR}=2.6-8.3)$. For all patients, 5 and 10-year progression-free survival was $95 \%$ $(95 \% \mathrm{CI}=89-98 \%)$ and $91 \%(95 \% \mathrm{CI}=82-96 \%)$. For CMT and chemotherapy alone patients, 5-year progression-free survival was $97 \%(95 \% \mathrm{CI}=91-99 \%)$ and $84 \%(95 \% \mathrm{CI}=57-$ 94\%), respectively (HR 0.21, 95\% CI $=0.05-0.91, p=0.02$; Figure 1). Corresponding 10-year values were $93 \%$ (95\% CI $=82-97 \%)$ and $84 \%(95 \% \mathrm{CI}=57-94 \%)$, respectively. On multivariate analysis, use of CMT was the only predictor of improved progression-free survival $(p=0.04)$.

For the entire cohort, 5 and 10-year overall survival were both $96 \%$ (95\%CI $=90-98 \%$ at 10 years). OS at 10 years for CMT was $96 \%(95 \% \mathrm{CI}=90-99 \%)$ and for chemotherapy alone was $94 \%$ (95\% CI=65-99\%) (HR 0.76, 95\%CI=0.09$6.29, p=0.80$; Figure 2). On multivariate analysis, CMT was not associated with improved survival. The only statistically significant factor was young age $(p=0.04)$.

Treatment after relapse. For those who relapsed, median time to progression after the completion of chemotherapy alone and CMT was 10 and 16 months, respectively. All three relapses in the chemotherapy alone group were at sites of initial disease involvement with one patient also having distant progression. One patient never achieved a second remission after multiple systemic therapies and is currently alive with disease and on brentuximab. One patient relapsed despite receiving a tandem autologous/non-myeloablative allogeneic stem cell transplant (SCT) and died of disease. One patient is alive and disease-free after salvage chemotherapy and autologous SCT.

In the CMT group, there were five confirmed relapses- two were in the previously irradiated field and three at distant sites. Two patients with isolated recurrences received local therapy, one with surgical excision and the other with additional RT. The remaining patients received salvage chemotherapy followed by autologous SCT. With a median follow up after recurrence of 7 years, there have been no deaths. 
Table I. Patient and treatment characteristics.

\begin{tabular}{|c|c|c|c|}
\hline Characteristic & CMT only $(\mathrm{n}=117)$ & CT only $(n=19)$ & Comparison \\
\hline Age (median; IQR) & $30(22-38)$ & $25(16-38)$ & $p=0.23$ \\
\hline Gender $(\mathrm{n}, \%)$ & & & $p=0.04$ \\
\hline Female & $63(54 \%)$ & $15(79 \%)$ & \\
\hline Male & $54(46 \%)$ & $4(21 \%)$ & \\
\hline Histologic subtype (n, \%) & & & $p=0.75$ \\
\hline Nodular sclerosis & $95(81 \%)$ & $16(84 \%)$ & \\
\hline Mixed cellularity & $15(13 \%)$ & $2(11 \%)$ & \\
\hline Lymphocyte rich & $2(2 \%)$ & $1(5 \%)$ & \\
\hline NOS & $5(4 \%)$ & & \\
\hline Stage $(\mathrm{n}, \%)$ & & & $p=0.57$ \\
\hline I & $15(13 \%)$ & $1(5 \%)$ & \\
\hline II & $102(87 \%)$ & $18(95 \%)$ & \\
\hline Number of nodal areas (median, range) & $2(1-6)$ & $3(1-5)$ & $p=0.16$ \\
\hline \multicolumn{4}{|l|}{ Risk Factors } \\
\hline$>2$ nodal areas $(\mathrm{n}, \%)$ & $47(40 \%)$ & $10(53 \%)$ & $p=0.31$ \\
\hline Extranodal disease $(\mathrm{n}, \%)$ & $4(3 \%)$ & $1(5 \%)$ & $p=0.69$ \\
\hline B symptoms present $(\mathrm{n}, \%)$ & $44(38 \%)$ & $6(32 \%)$ & $p=0.80$ \\
\hline Unfavorable ESR/B-symptom profile (n, \%) & $40(34 \%)$ & $7(37 \%)$ & $p=0.82$ \\
\hline LMA present $(\mathrm{n}, \%)$ & $41(35 \%)$ & $7(37 \%)$ & $p=0.75$ \\
\hline Favorable disease & $26(22 \%)$ & $6(32 \%)$ & $p=0.59$ \\
\hline \multicolumn{4}{|l|}{ Treatment } \\
\hline Chemotherapy cycles (median; range) & $6(2-8)$ & $6(3-6)$ & $p=0.85$ \\
\hline \multicolumn{4}{|l|}{ Chemotherapy } \\
\hline ABVD & $102(87 \%)$ & $15(79 \%)$ & $p=0.34$ \\
\hline ABVD hybrid & $5(4 \%)$ & & \\
\hline Other & $10(9 \%)$ & $4(21 \%)$ & \\
\hline Response assessment & & & $p=0.01$ \\
\hline PET & $71(61 \%)$ & $17(89 \%)$ & \\
\hline Gallium & $46(39 \%)$ & $2(11 \%)$ & \\
\hline Radiation dose (Gy, median; range) & $24(18-36)$ & N/A & \\
\hline
\end{tabular}

CMT: Combined modality therapy; CT: chemotherapy; IQR: interquartile range; NOS: not otherwise specified; LMA: large mediastinal adenopathy.

Table II. Secondary malignancies.

\begin{tabular}{|c|c|c|c|c|c|c|}
\hline Patient & Treatment & Secondary malignancy & $\begin{array}{l}\text { In RT } \\
\text { field }\end{array}$ & $\begin{array}{l}\text { Interval to } \\
\text { SPM }\end{array}$ & $\begin{array}{l}\text { F/U after } \\
\text { SPM }\end{array}$ & $\begin{array}{l}\text { Mortality } \\
\text { from SPM }\end{array}$ \\
\hline $41 \mathrm{M}$ & $\mathrm{ABVD} \times 6$ & $\begin{array}{l}\text { Papillary thyroid cancer } \\
\text { s/p thyroidectomy }\end{array}$ & N/A & $2 y$ & $5 y$ & No \\
\hline $23 \mathrm{~F}$ & $\mathrm{ABVD} \times 6+25.2 \mathrm{~Gy}$ & $\begin{array}{l}\text { Multiple basal cell carcinomas s/p } \\
\text { Mohs surgery and EDC }\end{array}$ & No & $10 y$ & $3 y$ & No \\
\hline $32 \mathrm{~F}$ & $\mathrm{ABVD} \times 6+19.8 \mathrm{~Gy}$ & $\begin{array}{l}\text { AML s/p chemotherapy, } \\
\text { died of sepsis }\end{array}$ & N/A & $1 \mathrm{y}$ & $<1 \mathrm{y}$ & Yes \\
\hline $43 \mathrm{~F}$ & $\mathrm{ABVD} \times 4+30 \mathrm{~Gy}$ & $\begin{array}{c}\text { Stage II follicular lymphoma } \\
\text { s/p RT }\end{array}$ & No & $3 y$ & $4 y$ & No \\
\hline $30 \mathrm{~F}$ & $\mathrm{ABVD} \times 5+24.3 \mathrm{~Gy}$ & $\begin{array}{l}\text { Colon cancer } \mathrm{s} / \mathrm{p} \text { colectomy and adjuvant } \\
\text { chemotherapy. Alive with recurrent disease. }\end{array}$ & No & $12 y$ & $6 y$ & No \\
\hline $30 \mathrm{M}$ & $\mathrm{ABVD} \times 6+27 \mathrm{~Gy}$ & $\begin{array}{c}\text { Basal cell carcinoma s/p } \\
\text { Mohs surgery }\end{array}$ & No & $11 \mathrm{y}$ & $3 y$ & No \\
\hline $40 \mathrm{M}$ & $\mathrm{ABVD} \times 6+23.4 \mathrm{~Gy}$ & $\begin{array}{c}\text { Small cell lung cancer } \mathrm{s} / \mathrm{p} \\
\text { chemotherapy }\end{array}$ & Yes & $13 y$ & $1 \mathrm{y}$ & Yes \\
\hline $42 \mathrm{M}$ & $\mathrm{ABVD} \times 6+24 \mathrm{~Gy}$ & $\begin{array}{l}\text { DLBCL with multiple relapses despite RT, } \\
\text { chemotherapy and autologous SCT }\end{array}$ & No & $2 y$ & $1 \mathrm{y}$ & Yes \\
\hline
\end{tabular}

M: Male; F: female; y: years; RT: radiation therapy; SPM: second primary malignancy; ABVD: adriamycin, bleomycin, vinblastine and dacarbazine; EDC: electrodessication and curettage; AML: acute myelogenous leukemia; SCT: stem cell transplant; DLBCL: diffuse large B-cell lymphoma. 


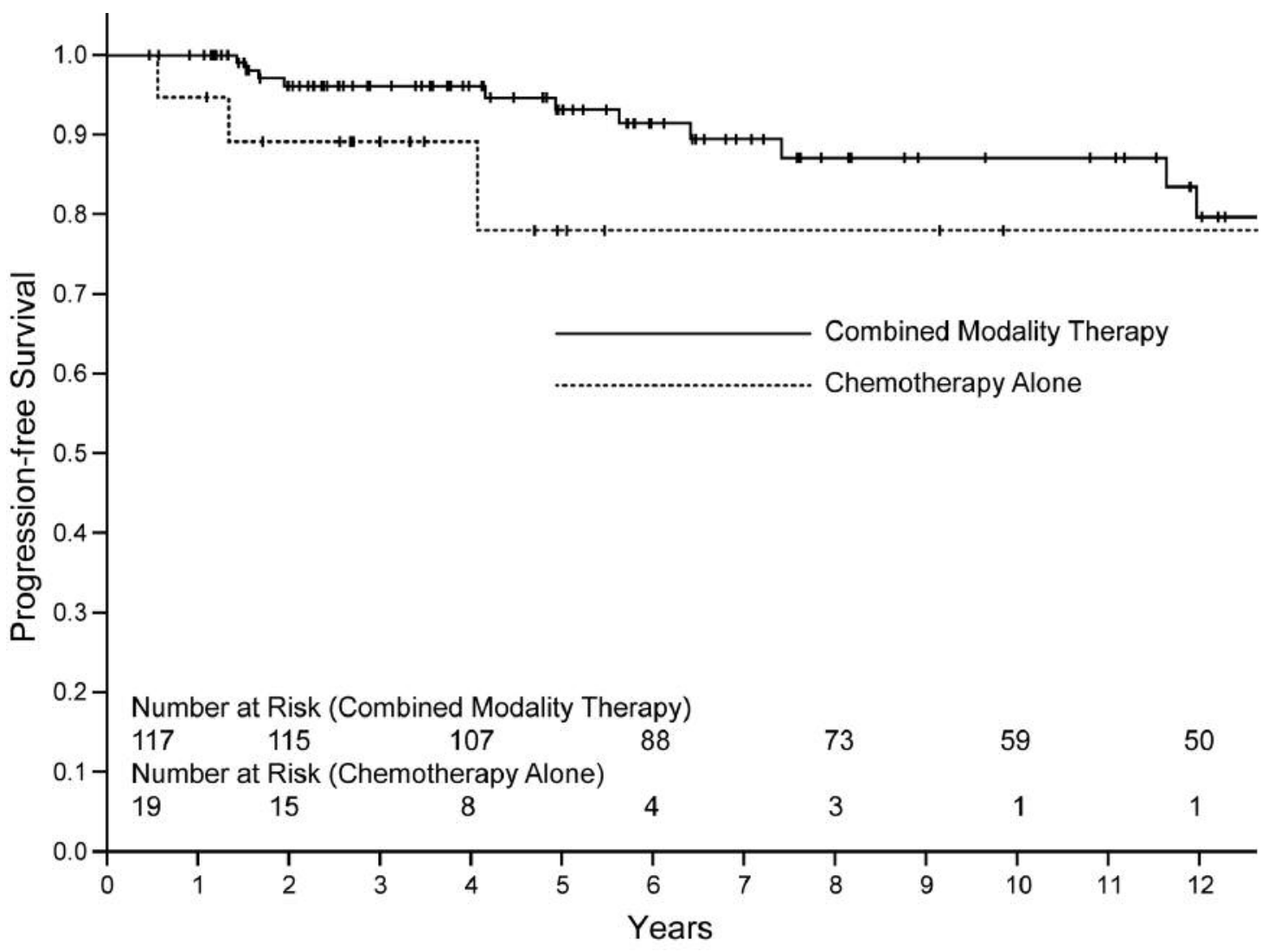

Figure 1. Kaplan-Meier curve of progression-free survival comparing combined modality therapy and chemotherapy alone.

Toxicity. Secondary malignancy risk in the CMT and chemotherapy alone groups was nearly equivalent at 10 years, with $3 \%(95 \% \mathrm{CI}=1-8 \%)$ and $6 \% \quad(95 \% \mathrm{CI}=1-35 \%)$, respectively (Table II and Figure 3). On multivariate analysis CMT was not associated with an increased risk of secondary malignancy risk (HR 0.50, 95\% CI=0.06-4.40, $p=0.5)$. Only one secondary malignancy, a papillary thyroid cancer, developed in the chemotherapy alone group. There were seven secondary neoplasms in the CMT group. These included acute myelogenous leukemia, follicular lymphoma, diffuse large B-cell lymphoma, small cell lung cancer, colon cancer, and two basal cell carcinomas. There were no cases of breast cancer. The small cell lung cancer was the only malignancy clearly arising within the RT field, occurring in an active smoker (13 years) after treatment. Three patients died of their secondary malignancies (acute myelogeneous leukemia, diffuse large B-cell lymphoma and small cell lung cancer).

A total of 28 patients in the CMT group developed hypothyroidism ( $24 \%$ crude incidence). There were no cardiac events during the follow-up period. No other significant late effects were noted.

\section{Discussion}

CMT and chemotherapy alone are both considered acceptable treatment approaches for early stage Hodgkin lymphoma, though CMT is considered standard for patients with bulky disease. As compared to chemotherapy alone, CMT has consistently resulted in superior disease control (4, 12). Our experience, in which all patients were in a complete response by functional imaging after combination chemotherapy, also demonstrated improved progression-free survival with CMT in early-stage HL. This aligns with findings from the randomized RAPID study which demonstrated a higher risk of relapse with chemotherapy alone even when a complete response by PET-CT was achieved with ABVD (5).

The absolute improvement in progression-free survival in our series was $\sim 10 \%$ which is consistent with other studies. Identifying those patients with residual disease after chemotherapy that would most benefit from consolidation RT has been elusive. A negative post-chemotherapy PET-CT is not informative, evidenced by both the RAPID (5) study and an Italian randomized trial (13). Interim PET-CT, while 


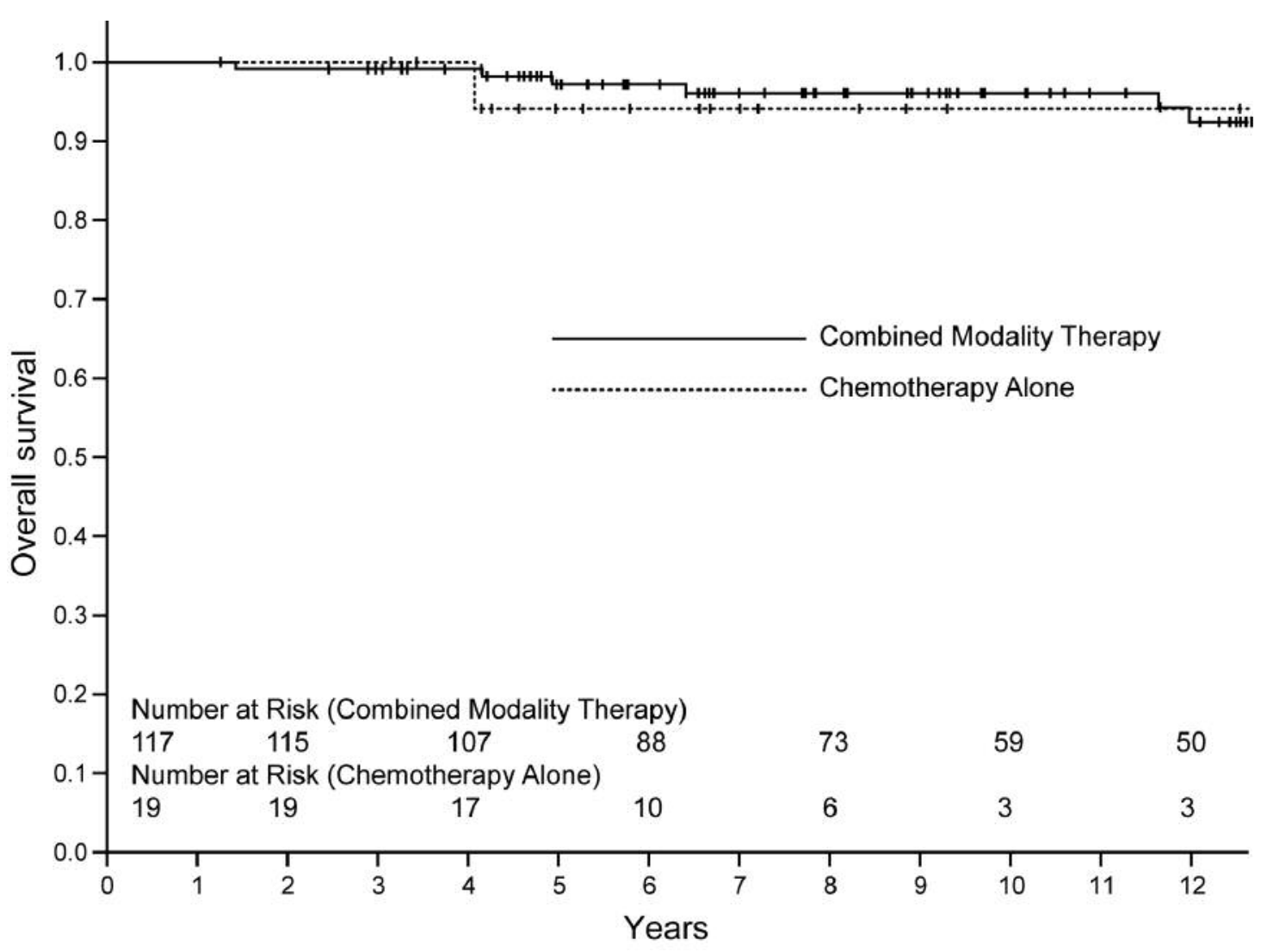

Figure 2. Kaplan-Meier curve of overall survival comparing combined modality therapy and chemotherapy alone.

highly prognostic, has not proven to be discriminatory based on the EORTC H10 study (14). Further studies are underway evaluating interim PET-CT by multiple cooperative groups. Admittedly, the majority of patients are ostensibly cured with chemotherapy alone. Additional efforts beyond PET-CT, incorporating underlying biological behavior, will likely prove necessary to identify the subset of patients who would most benefit from the addition of consolidation RT.

Despite improved disease control with CMT, concern about the late toxicity of RT and its potential impact on longterm survival has likely led to decreased utilization of CMT (6). Fortunately, there have been significant advances in radiation therapy delivery systems, an appreciation that lower doses are sufficient in all subgroups $(7,8)$, and utilization of smaller RT fields $(7,8)$. Smaller fields and lower doses decrease the risk of both secondary malignancies $(15-17)$ and cardiac toxicity $(18,19)$, thereby improving the therapeutic ratio of RT. Our study showed excellent longterm survival in CMT patients treated with a modern paradigm with no cases of cardiac toxicity and only two secondary malignancies that may have been attributed to RT (small cell lung cancer and AML). Longer follow-up is always desirable when assessing late effects of therapy.
Survival is a challenging endpoint in HL as some patients are salvaged with autologous stem cell transplantation and those who are not can live for many years with active disease. This is also an issue in large randomized trials of early-stage Hodgkin lymphoma where progression-free survival is typically the primary endpoint. A systematic review and meta-analysis of five randomized controlled trials which included 1,245 patients did, however, show improved overall survival in patients treated with CMT compared to chemotherapy alone (12). A recent analysis of a large national database has also shown chemotherapy alone results in inferior survival compared to CMT (6). While high dose chemotherapy followed by autologous stem cell rescue can salvage some patients, it has been reported to be successful in only $\sim 50 \%$ of patients who respond to initial second-line therapy and carries a significant risk of both treatmentrelated morbidity and mortality (20).

At our institution, patients with early-stage favorable disease are managed with 2 cycles of ABVD followed by 20 Gy of RT, based on the results of German Hodgkin Study Group (GHSG) HD10 (8). For patients with bulky mediastinal disease, we most frequently give 6 cycles of ABVD followed by 20 Gy of RT (7). The same approach is 


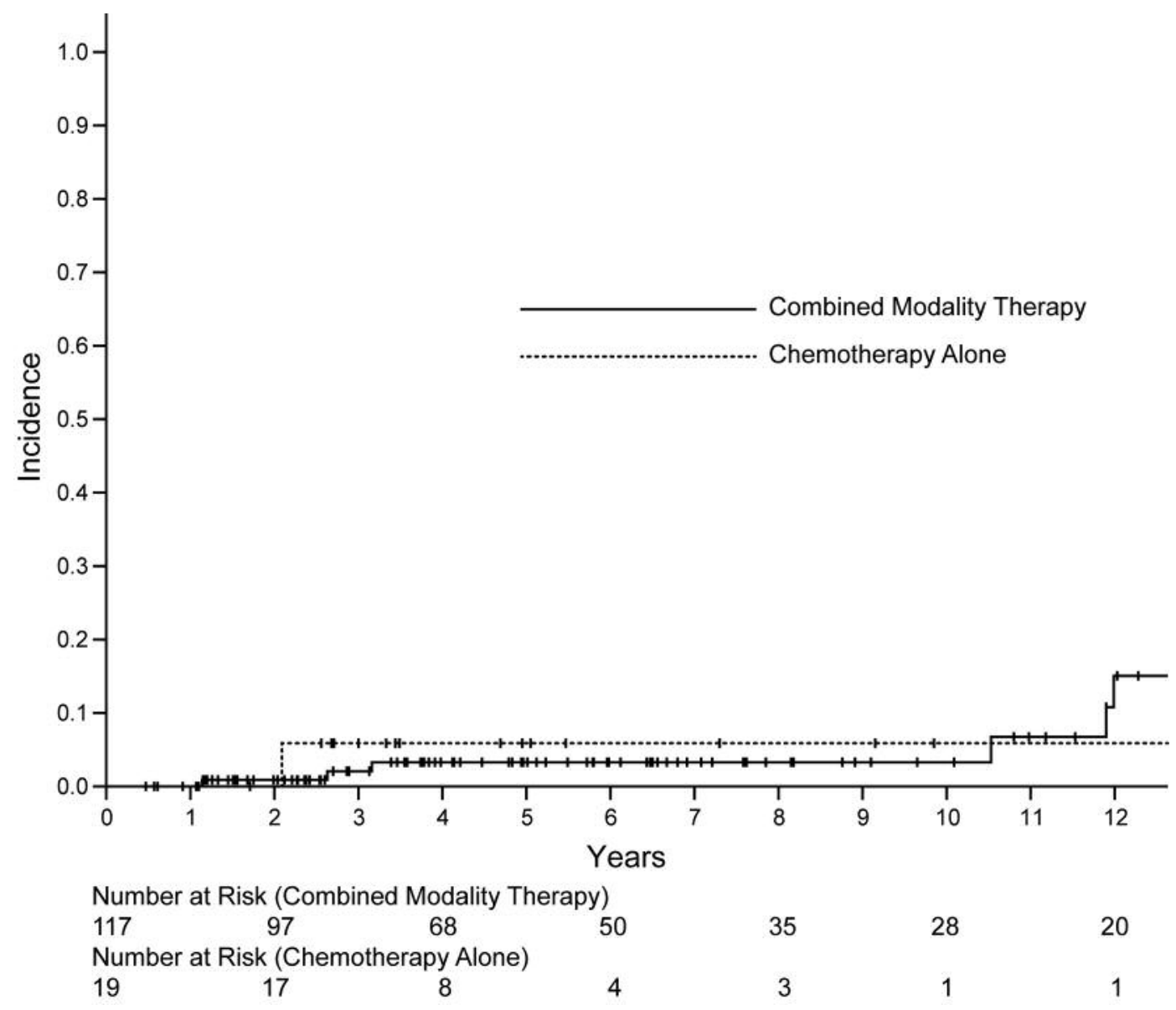

Figure 3. Cumulative incidence of secondary malignancies comparing combined modality therapy and chemotherapy alone.

commonly utilized in young patients, particularly females, with mediastinal and axillary disease where the risk of longterm adverse effects by $30 \mathrm{~Gy}$ of RT is of concern. After 4 cycles of ABVD for early-stage unfavorable disease, we do recommend 30 Gy based on GHSG HD11 (21).

As with all retrospective studies, there are limitations to our analysis. As our Institution typically prefers a CMT approach, there was only a relatively small number of patients treated with chemotherapy alone, who also had shorter follow-up than the CMT group. While follow-up was adequate to assess progression-free survival, longer follow-up is required to assess survival and the risk of late effects adequately.

\section{References}

1 Klimm B, Goergen H, Fuchs M, von Tresckow B, Boll B, Meissner J, Glunz A, Diehl V, Eich HT, Engert A and Borchmann P: Impact of risk factors on outcomes in early-stage hodgkin's lymphoma: An analysis of international staging definitions. Ann Oncol 24(12): 3070-3076, 2013.
2 Meyer RM, Gospodarowicz MK, Connors JM, Pearcey RG, Wells WA, Winter JN, Horning SJ, Dar AR, Shustik C, Stewart DA, Crump M, Djurfeldt MS, Chen BE, Shepherd LE, Group NCT and Eastern Cooperative Oncology G: Abvd alone versus radiation-based therapy in limited-stage hodgkin's lymphoma. $\mathrm{N}$ Engl J Med 366(5): 399-408, 2012.

3 Herbst $\mathrm{C}$ and Engert A: Meta-analyses of early-stage hodgkin lymphoma. Acta Haematol 125(1-2): 32-38, 2011.

4 Hay AE, Klimm B, Chen BE, Goergen H, Shepherd LE, Fuchs M, Gospodarowicz MK, Borchmann P, Connors JM, Markova J, Crump M, Lohri A, Winter JN, Dorken B, Pearcey RG, Diehl V, Horning SJ, Eich HT, Engert A, Meyer RM, Conducted by the NCTG and German Hodgkin Study G: An individual patientdata comparison of combined modality therapy and abvd alone for patients with limited-stage hodgkin lymphoma. Ann Oncol 24(12): 3065-3069, 2013.

5 Radford J, Illidge T, Counsell N, Hancock B, Pettengell R, Johnson P, Wimperis J, Culligan D, Popova B, Smith P, McMillan A, Brownell A, Kruger A, Lister A, Hoskin P, O'Doherty $\mathrm{M}$ and Barrington S: Results of a trial of pet-directed therapy for early-stage hodgkin's lymphoma. N Engl J Med 372(17): 1598-1607, 2015. 
6 Olszewski AJ, Shrestha R and Castillo JJ: Treatment selection and outcomes in early-stage classical hodgkin lymphoma: Analysis of the national cancer data base. J Clin Oncol 33(6): 625-633, 2015.

7 Torok JA, Wu Y, Prosnitz LR, Kim GJ, Beaven AW, Diehl LF and Kelsey CR: Low-dose consolidation radiation therapy for early stage unfavorable hodgkin lymphoma. Int J Radiat Oncol Biol Phys 92(1): 54-59, 2015.

8 Engert A, Plutschow A, Eich HT, Lohri A, Dorken B, Borchmann P, Berger B, Greil R, Willborn KC, Wilhelm M, Debus J, Eble MJ, Sokler M, Ho A, Rank A, Ganser A, Trumper L, Bokemeyer C, Kirchner H, Schubert J, Kral Z, Fuchs M, Muller-Hermelink HK, Muller RP and Diehl V: Reduced treatment intensity in patients with early-stage hodgkin's lymphoma. N Engl J Med 363(7): 640-652, 2010.

9 Campo E, Swerdlow SH, Harris NL, Pileri S, Stein H and Jaffe ES: The 2008 who classification of lymphoid neoplasms and beyond: Evolving concepts and practical applications. Blood 117(19): 5019-5032, 2011.

10 Carbone PP, Kaplan HS, Musshoff K, Smithers DW and Tubiana M: Report of the committee on hodgkin's disease staging classification. Cancer Res 31(11): 1860-1861, 1971.

11 Yahalom $\mathbf{J}$ and Mauch P: The involved field is back: Issues in delineating the radiation field in hodgkin's disease. Ann Oncol 13(Suppl 1): 79-83, 2002.

12 Herbst C, Rehan FA, Brillant C, Bohlius J, Skoetz N, Schulz H, Monsef I, Specht L and Engert A: Combined modality treatment improves tumor control and overall survival in patients with early stage hodgkin's lymphoma: A systematic review. Haematologica 95(3): 494-500, 2010.

13 Picardi M, De Renzo A, Pane F, Nicolai E, Pacelli R, Salvatore $\mathrm{M}$ and Rotoli B: Randomized comparison of consolidation radiation versus observation in bulky hodgkin's lymphoma with post-chemotherapy negative positron emission tomography scans. Leuk Lymphoma 48(9): 1721-1727, 2007.

14 Raemaekers JM, Andre MP, Federico M, Girinsky T, Oumedaly R, Brusamolino E, Brice P, Ferme C, van der Maazen R, Gotti M, Bouabdallah R, Sebban CJ, Lievens Y, Re A, Stamatoullas A, Morschhauser F, Lugtenburg PJ, Abruzzese E, Olivier P, Casasnovas RO, van Imhoff G, Raveloarivahy T, Bellei M, van der Borght T, Bardet S, Versari A, Hutchings M, Meignan M and Fortpied C: Omitting radiotherapy in early positron emission tomography-negative stage $\mathrm{i} / \mathrm{ii}$ hodgkin lymphoma is associated with an increased risk of early relapse: Clinical results of the preplanned interim analysis of the randomized eortc/lysa/fil h10 trial. J Clin Oncol 32(12): 1188-1194, 2014.
15 Koontz BF, Kirkpatrick JP, Clough RW, Prosnitz RG, Gockerman JP, Moore JO and Prosnitz LR: Combined-modality therapy versus radiotherapy alone for treatment of early-stage hodgkin's disease: Cure balanced against complications. J Clin Oncol 24(4): 605-611, 2006.

16 Salloum E, Doria R, Schubert W, Zelterman D, Holford T, Roberts KB, Farber LR, Kiehl RK, Cardinale J and Cooper DL: Second solid tumors in patients with hodgkin's disease cured after radiation or chemotherapy plus adjuvant low-dose radiation. J Clin Oncol 14(9): 2435-2443, 1996.

17 De Bruin ML, Sparidans J, van't Veer MB, Noordijk EM, Louwman MW, Zijlstra JM, van den Berg H, Russell NS, Broeks A, Baaijens MH, Aleman BM and van Leeuwen FE: Breast cancer risk in female survivors of hodgkin's lymphoma: Lower risk after smaller radiation volumes. J Clin Oncol 27(26): 42394246, 2009.

18 Schellong G, Riepenhausen M, Bruch C, Kotthoff S, Vogt J, Bolling T, Dieckmann K, Potter R, Heinecke A, Bramswig J and Dorffel W: Late valvular and other cardiac diseases after different doses of mediastinal radiotherapy for hodgkin disease in children and adolescents: Report from the longitudinal gpoh follow-up project of the german-austrian dal-hd studies. Pediatr Blood Cancer 55(6): 1145-1152, 2010.

19 Hull MC, Morris CG, Pepine CJ and Mendenhall NP: Valvular dysfunction and carotid, subclavian, and coronary artery disease in survivors of hodgkin lymphoma treated with radiation therapy. JAMA 290(21): 2831-2837, 2003.

20 Yuen AR, Rosenberg SA, Hoppe RT, Halpern JD and Horning SJ: Comparison between conventional salvage therapy and highdose therapy with autografting for recurrent or refractory hodgkin's disease. Blood 89(3): 814-822, 1997.

21 Eich HT, Diehl V, Gorgen H, Pabst T, Markova J, Debus J, Ho A, Dorken B, Rank A, Grosu AL, Wiegel T, Karstens JH, Greil R, Willich N, Schmidberger H, Dohner H, Borchmann P, MullerHermelink HK, Muller RP and Engert A: Intensified chemotherapy and dose-reduced involved-field radiotherapy in patients with early unfavorable hodgkin's lymphoma: Final analysis of the german hodgkin study group hd11 trial. J Clin Oncol 28(27): 4199-4206, 2010.
Received March 1, 2018

Revised March 16, 2018

Accepted March 19, 2018 